\title{
Increased levels of exhaled carbon monoxide in bronchiectasis: a new marker of oxidative stress
}

\author{
I Horvath, S Loukides, T Wodehouse, S A Kharitonov, P J Cole, P J Barnes
}

\begin{abstract}
Background-Bronchiectasis is a chronic inflammatory lung disease associated with increased production of oxidants due mostly to neutrophilic inflammation. Induction of heme oxygenase (HO-1) by reactive oxygen species is a general cytoprotective mechanism against oxidative stress. HO-1 catabolises heme to bilirubin, free iron and carbon monoxide (CO). Exhaled CO measurements may therefore reflect an oxidative stress and be clinically useful in the detection and management of inflammatory lung disorders. Methods-The levels of exhaled CO of 42 non-smoking patients with bronchiectasis treated or not treated with inhaled corticosteroids were compared with CO levels in 37 normal non-smoking subjects. Results-Levels of exhaled CO were raised in patients with bronchiectasis, both those treated with inhaled corticosteroids ( $\mathrm{n}=27$, median $5.5 \mathrm{ppm}, \mathbf{9 5 \%}$ CI 5.16 to 7.76 ) and those not treated with inhaled corticosteroids ( $n=15$, median 6.0 ppm, $95 \%$ CI 4.74 to 11.8 ), compared with normal subjects $(\mathrm{n}=37$, median $3.0 \mathrm{ppm}$, $95 \%$ CI 2.79 to $3.81, p=0.0024)$. There was no correlation between exhaled $\mathrm{CO}$ and HbCO levels $(r=0.42, p=0.12)$ in normal subjects $(n=7)$, nor between the urine cotinine concentration and exhaled $\mathrm{CO}$ levels $(r=0.2, p=0.12)$.
\end{abstract}

Conclusions-Increased levels of exhaled CO may reflect induction of $\mathrm{HO}-1$ and oxidative stress in bronchiectasis. Measurement of exhaled CO may be useful in the management of bronchiectasis and possibly other chronic inflammatory lung disorders.

(Thorax 1998;53:867-870)

Keywords: exhaled carbon monoxide; bronchiectasis; heme oxygenase

Oxidative stress and reactive oxygen species have been implicated in the pathogenesis of many pulmonary diseases including chronic inflammatory lung disorders such as asthma, chronic obstructive pulmonary disease (COPD), and bronchiectasis. ${ }^{1-3}$ Reactive oxygen species, including the superoxide anion $\left(\mathrm{O}_{2}^{-}\right)$, hydroxyl radicals, and hydrogen peroxide $\left(\mathrm{H}_{2} \mathrm{O}_{2}\right)$, are produced by activated immune and inflammatory cells ${ }^{3-5}$ and cause oxidation of nucleic acids, proteins, and membrane lipids. ${ }^{4}$ One of the mechanisms protecting against an oxidative stress is the induction of a stress response protein, heme oxygenase $(\mathrm{HO}) \cdot{ }^{7-10} \mathrm{HO}-1$, an inducible form of $\mathrm{HO}$, catalyses the degradation of heme to bilirubin, and consequently to the anti-oxidant bilirubin, producing free iron and carbon monoxide $(\mathrm{CO})^{11}$ which has several biological activities including stimulation of guanylate cyclase. ${ }^{12-14}$ Some other inflammatory mediators such as cytokines and nitric oxide (NO) are also released during chronic inflammation and are able to induce HO-1 expression. $^{78}$

Exhaled NO levels are raised in patients with bronchiectasis, ${ }^{15}$ reflecting the chronic inflammatory process. ${ }^{16} \mathrm{~A}$ vicious circle of microbial colonisation and host derived inflammation leads to damage of adjacent normal lung tissue $^{17}$ with neutrophilic infiltration and high levels of proinflammatory cytokines present in airway secretions, ${ }^{18}{ }^{19}$ resulting in overproduction of $\mathrm{O}_{2}^{-}$and other oxidants. ${ }^{4}$

We therefore postulated that measurement of CO levels in the breath of patients with bronchiectasis may reflect $\mathrm{HO}-1$ activation and may provide useful information on the control of inflammation and the assessment of new anti-inflammatory treatments.

\section{Methods}

PATIENTS

Forty two non-smoking patients (16 men) of mean age 45 (15) years, forced expiratory volume in one second $\left(\mathrm{FEV}_{1}\right) \quad 59 \quad(19.5) \%$ predicted, carbon monoxide transfer factor (TLCO) 88 (4.4)\% predicted with clinically and radiologically diagnosed bronchiectasis confirmed by high resolution computed tomographic (CT) scanning of the thorax were studied. All were clinically stable and had no evidence of acute infective exacerbations for at least four weeks prior to the study. Bronchiectasis was believed to be secondary to tuberculosis in two cases, to primary ciliary dyskinesia in 10, to IgA deficiency in two cases, to a deficiency of a subclass of IgG in three, and with no definite antecedent cause identified in the remaining patients (idiopathic). Patients with cystic fibrosis, allergic bronchopulmonary aspergillosis, asthma, and atopic diseases were excluded. Fifteen patients were taking regular inhaled $\beta_{2}$ agonists and 27 were on inhaled corticosteroids (fluticasone propionate, 500$2000 \mu \mathrm{g}$ daily). Thirty seven normal nonsmoking subjects (20 men) of mean age 33 (17.1) years were free of respiratory infections for at least six weeks before starting the study, had no history of chronic cardiovascular or respiratory disease, and were not receiving any regular medication. These subjects had a negative history of allergy (negative skin prick tests to common allergens), normal spirometric 
values $\left(\mathrm{FEV}_{1} 94 \quad(4.9) \%\right.$ predicted), and normal bronchial reactivity with a provocative concentration of methacholine causing a $20 \%$ fall in $\mathrm{FEV}_{1}\left(\mathrm{PC}_{20}\right)$ of $>32 \mathrm{mg}$ in all subjects.

The subjects were tested by NicCheck I (DynaGe Inc, Cambridge, Massachusetts, USA) which determines the levels of cotinine in urine to ensure non-smoking status. Active and passive smokers (smoke exposure for more than 0.5 hour/day) were excluded from the study. In addition, $\mathrm{HbCO}$ was measured in blood in seven normal volunteers and compared with their exhaled CO levels.

The study was approved by the ethics committee of the Royal Brompton Hospital.

\section{MEASUREMENTS}

$\mathrm{FEV}_{1}$ was measured using a dry spirometer (Vitalograph, Buckingham, UK) and the best value of three manoeuvres was expressed as a percentage of the predicted value. Airway responsiveness was measured by methacholine provocation challenge (Dosimeter MB3; MEFAR, Boveza, Italy). The $\mathrm{PC}_{20}$ was calculated by interpolation of the logarithmic doseresponse curve.

Exhaled CO was measured using a modified Micro Smokerlyser (Bedfont Scientific UK) sensitive to CO from 0 to 500 parts per million (ppm, by volume), adapted for on-line recording of $\mathrm{CO}$ concentration and integrated with a chemiluminescence analyser (Model LR2000, Logan Research, UK) to control exhalation parameters. Exhaled CO was not measured on the day of TLCO assessment to exclude the influence of inhaled gas mixture containing $0.3 \%$ CO on exhaled CO levels. The subjects exhaled slowly from functional vital capacity with a constant flow (5-6 1/min) against a low resistance $(3(0.4) \mathrm{mm} \mathrm{Hg})$ over $20-30 \mathrm{~s}$ into the analyser. Two successive recordings were made and the highest value was used in all calculations. Ambient CO levels were recorded before the measurements.

STATISTICAL ANALYSIS

The data are presented as medians and ranges. The results of the studied groups were compared by the Mann-Whitney U test and estimates of the differences between groups were expressed as medians and 95\% confidence intervals (CI). Spearman's rank correlation coefficient was used to test the relationships between variables. A $p$ value of $<0.05$ was considered significant.

\section{Results}

Exhaled CO was detectable in all subjects. The levels of exhaled CO were significantly increased in patients with bronchiectasis $(n=42)$ compared with healthy subjects (median 6.0 ppm, 95\% CI 5.58 to $8.57 \mathrm{ppm}$ versus median $3.0 \mathrm{ppm}, 95 \%$ CI 2.79 to $3.81 \mathrm{ppm}, \mathrm{p}=$ 0.0024 ; fig 1 ). There was no difference in exhaled CO levels between 27 steroid treated patients and 15 non-treated patients (median $5.5 \mathrm{ppm}, 95 \% \mathrm{CI}-5.16$ to $7.76 \mathrm{ppm}$ versus median $6.0 \mathrm{ppm}, 95 \% \mathrm{CI} 4.47$ to $11.8 \mathrm{ppm}, \mathrm{p}$ $=0.08)$. There was a tendency for a negative correlation between lung function as assessed

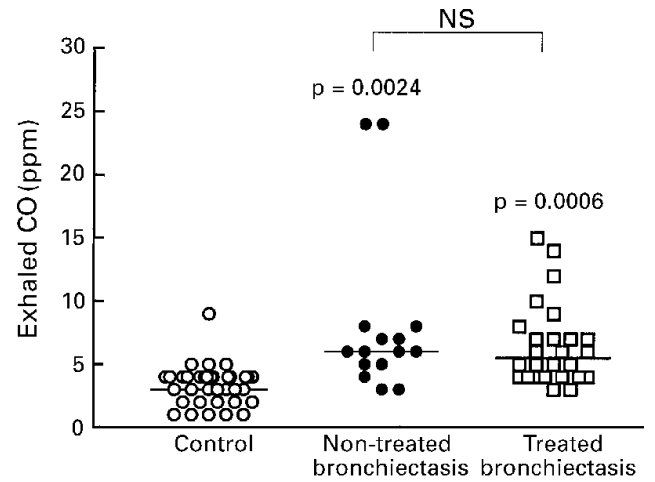

Figure 1 Exhaled CO concentrations in normal subjects $(n=37)$, patients with bronchiectasis not treated with inhaled steroids $(n=15)$, and patients with bronchiectasis treated with inhaled steroids $(n=27)$.

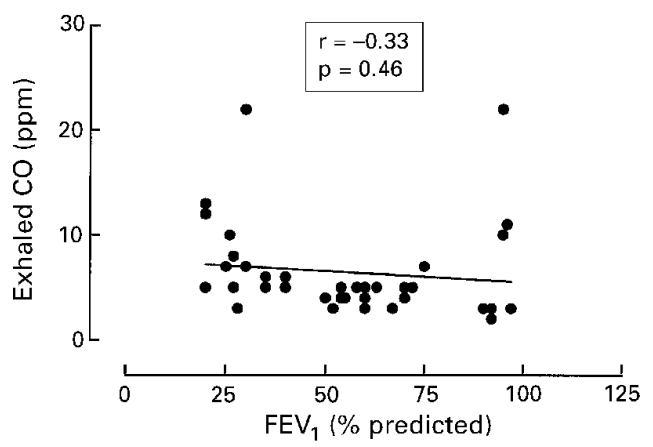

Figure 2 Correlation between exhaled $C O$ and $F E V_{1} \%$ predicted in patients with bronchiectasis $(n=42)$.

by $\mathrm{FEV}_{1}$ and exhaled $\mathrm{CO}$ levels $(r=-0.33, \mathrm{p}=$ 0.46 ; fig 2 ). There was no correlation between exhaled $\mathrm{CO}$ and $\mathrm{HbCO}$ levels $(r=0.42, \mathrm{p}=$ 0.12 ) in normal subjects $(n=7)$. The urinary levels of cotinine were compared with exhaled $\mathrm{CO}$ concentrations in all normal subjects and patients with bronchiectasis and no correlation was found $(r=0.2, \mathrm{p}=0.12)$.

\section{Discussion}

The results of this study show that exhaled CO is increased in patients with bronchiectasis, irrespective of their anti-inflammatory treatment, which might be a reflection of oxidative stress and HO-1 activation.

The source of $\mathrm{CO}$ in exhaled air of non-smoking subjects is uncertain. It is likely that exhaled $\mathrm{CO}$ derives from an endogenous source since the inhaled $\mathrm{HO}$ inhibitor, tinmesoporphyrin, significantly inhibits the concentration of CO (unpublished observations). The technique used in the present study with a single expiratory manoeuvre against resistance is known to minimise the upper respiratory and ambient air contribution to the exhaled CO.

Bronchiectasis is a chronic inflammatory airway disease which is characterised by neutrophil dominant airway inflammation and damage to bronchial epithelial cells. Increased HO-1 protein expression may be due to the induction of the enzyme by inflammatory cytokines and oxidants such as interleukins, tumour necrosis factor- $\alpha$, interferon- $\gamma$, and $\mathrm{H}_{2} \mathrm{O}_{2}$ which are capable of inducing HO-1 expression in cell lines and tissues. ${ }^{7} 810$ The increase in exhaled $\mathrm{CO}$ levels in patients with 
bronchiectasis may be explained by an increased activity of HO-1 expression in the airways of these patients.

The cellular source of $\mathrm{CO}$ in bronchiectasis is not known. Airway macrophages and neutrophils are known to be activated in bronchiectasis and may produce superoxide anions leading to increased $\mathrm{HO}-1$ expression. ${ }^{3} \mathrm{HO}-1$ may also be induced in various cells in the respiratory tract including epithelial cells and infiltrating inflammatory cells. ${ }^{7}$ Bacterial infections may contribute to oxidative stress by facilitating the recruitment and activation of phagocytic cells in the lung.

It has been shown that $\mathrm{HbCO}$ is strongly related $(r=0.97, \mathrm{p}<0.0001)$ to exhaled $\mathrm{CO}$ in smokers in whom $\mathrm{HbCO}$ values range from 0 to $15 \%$ and exhaled $\mathrm{CO}$ from 0 to $100 \mathrm{ppm}^{20}$ However, there is no relationship between $\mathrm{HbCO}$ values ranging from 0 and $2 \%$ and exhaled CO from 0 to $10 \mathrm{ppm}$ which are characteristic of non-smokers. All our subjects were non-smokers and there was no correlation between exhaled $\mathrm{CO}$ and $\mathrm{HbCO}$ in seven normal subjects whose blood samples were taken for $\mathrm{HbCO}$ analysis and compared with their exhaled CO levels.

In the present study no significant correlation was observed between exhaled CO concentration and $\mathrm{FEV}_{1} \%$ predicted, although patients with milder disease tended to have lower $\mathrm{CO}$ values. Higher exhaled $\mathrm{CO}$ values may be related to more intense inflammation; however, further studies measuring other inflammatory parameters are needed to confirm this hypothesis. There is some evidence that patients with bronchiectasis treated with inhaled steroids may benefit by a reduction in sputum production and improved lung function. ${ }^{21}$ However, no inflammatory markers were used in that study to confirm the anti-inflammatory action of steroids. The present study shows that patients with bronchiectasis treated with inhaled steroids tended to have lower levels of exhaled $\mathrm{CO}$ than patients not receiving steroids, but the difference was not statistically significant. This observation may be explained by the relative ineffectiveness of steroids on neutrophils, as was recently shown by studies of induced sputum from patients with asthma and COPD. ${ }^{22}$ This study, however, was designed as cross sectional and cannot clearly demonstrate a causal relationship between steroids and exhaled CO. Controlled studies are needed for that purpose. The lack of a significant effect of inhaled steroid therapy on exhaled CO is in contrast to the reduced levels of exhaled NO in bronchiectasis patients treated with inhaled steroids compared with untreated patients. This may reflect the fact that $\mathrm{NO}$ is derived from steroid responsive cells such as epithelial cells and macrophages, rather than from neutrophils.

The effect of increased production of endogenous $\mathrm{CO}$ on airway function in patients with bronchiectasis is uncertain. The induction of HO-1 has been suggested to play a part in the antioxidant response. ${ }^{78}$ By degrading heme and by generating bilirubin, an antioxidant that can scavenge hydroxyl radicals in vitro as efficiently as $\alpha$-tocopherol, induction of $\mathrm{HO}-1$ may provide an antioxidant protection. ${ }^{10}{ }^{16} \mathrm{CO}$, a by-product of $\mathrm{HO}$ activity, activates guanylate cyclase and is a putative neurotransmitter. ${ }^{13}{ }^{14}$ However, when produced in high concentrations by $\mathrm{HO}-1, \mathrm{CO}$ may have proinflammatory effects since it is also a potent vasodilator and may increase plasma exudation from airway vessels. Free iron, another end product of HO-1, can act as catalyst in the formation of reactive oxygen species and through this mechanism it may have inflammatory effects. However, the latter also induces ferritin expression which may serve to restrict iron from participation in the Fenton reaction, thereby reducing the oxidant burden of the cell. ${ }^{923}$ The induction of HO-1 has been shown to participate in the resolution of acute inflammation under experimental conditions and it has been suggested that it may play a cytoprotective role in haeme and oxidant-induced cellular injuries. ${ }^{24}$ These observations raise the possibility that overexpression of HO-1 may be beneficial in the treatment of chronic inflammatory diseases.

Measurement of exhaled CO, a putative index of HO activity, may be a simple method of detecting and monitoring cytokine mediated inflammation and oxidative stress in the respiratory tract and of assessing anti-inflammatory treatments. As CO measurement is simple, reproducible and non-invasive, it may be useful in children and in patients with severe disease who may not tolerate more invasive investigation. Further studies are needed, however, to relate expired $\mathrm{CO}$ levels to the extent of inflammation and to explore this approach in other inflammatory lung diseases.

The authors acknowledge the European Respiratory Society and the Hungarian National Scientific Research Foundation (OTKA-F01 7050), and the British Lung Foundation (UK).

1 Rahman I, Morrison D, Donaldson K. Systemic oxidative stress in asthma, COPD and smokers. Am $\mathcal{F}$ Respir Crit Care Med 1996;154:1055-60.

2 Repine JE, Bast A, Lankhorst I. Oxidative stress in chronic obstructive pulmonary disease. State of art. Am $\mathcal{F}$ Respir
ond obstructive pulmonary disease. Sta
Crit Care Med 1997;156:341-57.

3 Barnes PJ. Reactive oxygen species and airway inflammation. Free Radic Biol Med 1990;9:235-43.

4 Kinnula VL, Crapo JD, Raivio KO. Biology of disease. Generation and disposal of reactive oxygen metabolises in the lung. Lab Invest 1995;73:3-19.

5 Tonnel AB, Wallaert B. Oxidants and bronchial inflammation processes. Eur Respir F 1990;3:987-8.

6 Schraufstatter IU, Revak SD, Cochrane CG. Proteases and oxidants in experimental pulmonary inflammatory injury. $\mathcal{F}$ Clin Invest 1984;73:1175-84.

7 Choi AMK, Alam J. Heme oxygenase-1: function, regulation, and implication of a novel stress-inducible protein in oxidant-induced lung injury. Am 7 Respir Cell Mol Biol 1996;15:9-19.

8 Chambi S, Lee P, Choi AMK. The oxidative stress response. New Horizons 1995;3:170-82.

9 Vogt BA, Alam J, Croatt AJ, et al. Acquired resistance to acute oxidative stress. Possible role of heme oxygenase and ferritin. Lab Invest 1995;72:474-83.

10 Abraham NG, Drummond GS, Lutton JD, et al. The biological significance and physiological role of heme oxygenase. Cell Physiol Biochem 1996;6:129-68.

11 Tenhunen R, Marver HS, Schmid R. The enzymatic conversion of heme to bilirubin by microsomal heme oxygenase. Proc Natl Acad Sci USA 1968;61:748-55.

12 Stocker R, Yamamoto Y, McDonagh AF, et al. Bilirubin is an antioxidant of possible physiological importance. Science 1987;235:1043-5.

13 Dawson TM, Snyder SH. Gases as biological messengers: nitric oxide and carbon monoxide in the brain. $f$ Neurosci 1994:14:5147-9.

14 Morita T, Perrella MA, Lee ME, et al. Smooth muscle cellderived carbon monoxide is a regulator of vascular cGMP. Proc Natl Acad Sci USA 1995;92:1475-9. 
15 Kharitonov SA, Wells AU, O'Connor BJ, et al. Elevated levels of exhaled nitric oxide in bronchiectasis. Am $\mathcal{F}$ Respir

16 Cole PJ. A new look at the pathogenesis and management of persistent bronchial sepsis: a "vicious circle" hypothesis and its logical therapeutic connotations. In: Davies RJ, ed. Strategies for the management of bronchial sepsis. Oxford: Medicine Publishing Foundation, 1984: 1-20.

17 Cole PJ, Wilson R. Host-microbial interrelationships in respiratory infection. Chest.1989;95:217S-21S.

18 Eller J, Lapa e Silva JR, Poulter LW, et al. Cells and cytokines in chronic bronchial infection. Ann NY Acad Sci 1994;725: 331-45.

19 Currie DC, Saverymuttu SH, Peters AM, et al. Indiumlabelled granulocyte accumulation in the respiratory tract of patients with bronchiectasis. Lancet 1987;i:1335-9.
20 Jarvis MJ, Russell MAH. Expired air carbon monoxide: a simple breath test of tobacco smoke intake. BMF $1980 ; 3: 484-5$

21 Elborn JS, Johnston B, Allen F, et al. Inhaled steroids in patients with bronchiectasis. Respir Med 1992;86:121-4.

22 Keatings VM, Jatakanon A, Worsdell MY, et al. Effects of inhaled and oral glucocorticoids on inflammatory indices in asthma and COPD. Am 7 Respir Crit Care Med 1997;155:542-8

23 Morris CJ, Earl MJ, Trenam CW, et al. Reactive oxygen species and iron: a dangerous partnership in inflammation. Int f Biochem Cell Biol 1995;27:109-22.

24 Willis D, Moore AR, Frederick R, et al. Heme oxygenase: a novel target for the modulation of the inflammatory response. Nature Med 1996;2:87-9. 